\title{
A IMPORTÂNCIA DA COMUNICAÇÃO: FAMILIARES DE PACIENTES INTERNADOS EM UM CENTRO DE TERAPIA INTENSIVA
}

\author{
THE IMPORTANCE OF \\ COMMUNICATION: FAMILY \\ MEMBERS OF PATIENTS AT \\ AN INTENSIVE CARE UNIT
}

\author{
Esleane Vilela Vasconcelos* \\ Karina de Oliveira Freitas ** \\ Rafael Santana Costa Torres*** \\ Silvio Éder Dias da Silva ${ }^{* * * *}$ \\ Ronaldo de Sousa Moreira Baia***** \\ Jeferson Santos Araújo \\ Jéssica Oliveira da Cunha* \\ Gilmaira Pires Filgueira*
}

\section{RESUMO}

Este artigo teve origem no projeto de extensão "O cotidiano de familiares de pacientes internados no Centro de Terapia Intensiva (CTI)", tendo como objetivos avaliar o grau de satisfação dos familiares de pacientes internados no CTI para com a assistência recebida; informar os principais momentos que a equipe de saúde instituiu a comunicação com os familiares dos pacientes internados no CTI e verificar se os familiares confiam nas informações recebidas. Trata-se de um estudo qualitativo, descritivo, realizado no CTI do Hospital Universitário João de Barros Barreto, em Belém do Pará, de maio a julho de 2015, com 40 familiares, através de entrevista semiestruturada e analisada pela técnica de análise de conteúdo. Os resultados apontam três categorias: O primeiro contato com o CTI: a importância da comunicação; Quando a equipe de saúde fala comigo e Comunicação versus confiança. Esse estudo demonstrou que a comunicação em saúde, quando utilizada adequadamente, torna-se uma excelente ferramenta no cuidado em saúde.

Palavras chave: Comunicação. Enfermagem. Família. Terapia Intensiva.

\footnotetext{
* Professora da Universidade Federal do Pará (UFPA), PA - Brasil. E-mail: leanevas@hotmail.com

** Graduada pela Universidade Federal do Pará (UFPA), PA - Brasil. E-mail: kof-2011@hotmail.com

*** Aluno de Graduação da Universidade Federal do Pará (UFPA), PA - Brasil. E-mail: rsct22@gmail.com

**** Professor da Universidade Federal do Pará (UFPA), PA - Brasil. E-mail: silvioeder2003@yahoo.com.br

***** Professor da Universidade Federal do Pará (UFPA), PA - Brasil. E-mail: ronaldobaiaufpa@hotmail.com

****** Aluno de Doutorado da Universidade de São Paulo (USP), SP - Brasil. E-mail: jefaraujo@usp.br

******** Aluna de Graduação da Universidade Federal do Pará (UFPA), PA - Brasil. E-mail: jessicaoliveira_cunha@yahoo.com.br

******** Aluna de Graduação da Universidade Federal do Pará (UFPA), PA - Brasil. E-mail: gilmaira_enfermagem@hotmail.com
} 


\section{ABSTRACT}

This article is based on the experience gained with the outreach project "The routine of family members of patients at an Intensive Care Unit (ICU). It aims to evaluate the level of satisfaction of the family members of patients at the ICU concerning the assistance they received; inform the key moments when the health team established communication with family members at the ICU and verify if the family members trust the information received. It is a qualitative, descriptive study carried out at the ICU of the University Hospital João de Barros Barreto, in Belém do Pará from May to July 2015. The data consisted of semi-structured interviews conducted with 40 family members and analyzed according to content analysis technique. The results point out three categories: The first contact with the ICU: the importance of communication; The moments when the health team talk to family members and Communication versus confidence. This study demonstrated that when communication in health settings is effective it becomes an excellent tool in health care.

Keywords: Communication. Nursing. Family. Intensive care.

\section{Introdução}

O presente artigo foi elaborado a partir do projeto de extensáo intitulado "O cotidiano de familiares de pacientes internados no Centro de Terapia Intensiva (CTI)" que, em sua segunda versão, teve como foco a comunicaçáo estabelecida pela equipe intensivista com os familiares de pacientes internados no CTI, haja vista que esta foi uma das necessidades identificadas em sua primeira versão.

O projeto contava com quatro alunos de enfermagem, dois bolsistas e duas voluntárias que realizavam atividades de orientaçôes e esclarecimentos de dúvidas dos familiares de pacientes internados no CTI, referentes ao ambiente intensivo e aos cuidados ali ofertados. Tais alunos se dedicavam ao projeto duas vezes por semana, sendo um dupla às segundas e quintas-feiras e a outra dupla nas quartas e sextas-feiras.

Além das atividades citadas anteriormente, o projeto também estipulava a execução de atividades como a distribuição de impressos, confeccionados pelos acadêmicos, relacionados ao CTI; a realização de rodas de conversa; grupos de apoio e aplicaçáo de palestras para a equipe de enfermagem do CTI, sendo as mesmas sobre humanização, acolhimento e comunicação em saúde.

Durante o desenvolvimento das atividades, surgiram elogios e agradecimentos pela criação do projeto, tanto pela equipe de saúde quanto pelos familiares, principalmente pelos familiares, haja vista que o projeto supria ou pelo menos minimizava as suas necessidades de acolhimento. Dahdah et al (2013) informam que o acolhimento é um instrumento de grande valia para os serviços de saúde, dado que auxilia na diminuição da ansiedade e no processo de superação dos acontecimentos negativos, como a internação de um ente querido no CTI.

No que concerne à equipe de enfermagem, reconhecia a importância do projeto e de se ter um tempo de dedicaçáo aos familiares dos pacientes internados no CTI, no entanto alegavam que devido aos poucos recursos humanos disponíveis e a grande carga de trabalho e atenção que o serviço intensivo exigia e exige, era difícil se afastarem do CTI para acolher o familiar. Desta maneira, o projeto pode preencher algumas das lacunas existentes naquele CTI, no quesito assistência ao familiar.

Através desses momentos, visualizou-se a oportunidade de se executar uma pesquisa que pudesse mostrar aos profissionais de saúde e para a sociedade em geral a importância da comunicaçáo nos ambientes de saúde. De acordo com Aguiar et al (2012), nas práticas hospitalares, a comunicação é um meio que tende à potencializar a interação entre profissionais de saúde, pacientes e seus familiares, sendo também um desafio para alguns profissionais, especialmente para aqueles que cuidam de pacientes 
internados no CTI, pelo fato de a mesma tornar possível a manifestação e exteriorização do que se passa no interior de cada ser humano (OLIVEIRA, 2012).

Segundo Oliveira et al (2015) e Girardon-Perlini et al (2012;), a comunicação é um processo ativo que atravessa o contexto social e/ou psicossocial e é desenvolvido por meio das interaçóes entre os indivíduos, no qual um transfere a informação e o outro a recebe e compreende.

Assim a problematização deste estudo se resume a uma indagação: Qual a percepção dos familiares de pacientes internados no CTI com relação à comunicação instituída entre eles e os profissionais de saúde? E tem por objetivo geral: avaliar o grau de satisfação dos familiares de pacientes internados no CTI para com a assistência recebida; e específicos: informar os principais momentos no qual a equipe de saúde instituiu a comunicação com os familiares dos pacientes internados no CTI e se os familiares confiam nas informaçóes recebidas.

O alcance desses objetivos contribuirá para o preenchimento de lacunas existentes sobre o processo de comunicaçáo dos familiares com a equipe multiprofissional do ambiente intensivo e para uma nova visão de assistência em saúde.

\section{Metodologia}

Estudo de abordagem qualitativa descritiva e de campo que foi realizado no Centro de Terapia Intensiva do Hospital Universitário da Joáo de Barros Barreto, situado na capital de Belém, no estado do Pará-Brasil, no período de maio a julho de 2015.

Foram entrevistados 40 familiares de pacientes internados nessa UTI, que manifestaram disponibilidade e interesse em participar do estudo após o conhecimento dos objetivos da pesquisa e assinatura do termo de consentimento livre e esclarecido. $\mathrm{O}$ critério de inclusão utilizado foi: ser familiar, ter acima de 18 anos e ter estabelecido contato com pelo menos duas pessoas da equipe de saúde do CTI. Os familiares que não atendiam aos critérios eram somente orientados quanto aos cuidados do CTI e não participaram da pesquisa.

A coleta dos dados se deu por meio de entrevista semiestruturada, guiada por um roteiro composto pelos seguintes questionamentos: Como foi o seu primeiro contato com a equipe de saúde no CTI? Você sentiu confiança na comunicação estabelecida entre você e o profissional de saúde do CTI? Por quê? Você saberia dizer quais profissionais estabeleceram comunicação com você?? Em quais momentos? A observação participante também foi utilizada durante as entrevistas que ocorreram na sala de visita, onde os familiares aguardavam para visitação na UTI. Para a análise do material coletado foi empregada à técnica de análise de conteúdo temático.

A técnica de análise de conteúdo adotada se divide nas seguintes etapas: $1^{\circ}$ - Préanálise: primeiro contato com o conteúdo a ser avaliado, favorecendo a organizaçáo do material e a leitura das entrevistas até a saturação das ideias que surgirão; $2^{\circ}$ - Exploração do Material: transformação dos dados brutos, visando alcançar o núcleo de compreensão do texto e por fim $3^{\circ}$ - O tratamento dos resultados: a inferência e a interpretação. (BARDIM, 2009).

As unidades de análise criadas foram agrupadas e submetidas a uma exploração para melhor compreensão do objeto da pesquisa, mediante conteúdos considerados 
mais significativos em cada texto, de forma a se consolidarem em três unidades assim denominadas: "O primeiro contato com o CTI: a importância da comunicação"; "Quando a equipe de saúde fala comigo!" e "Comunicação versus confiança". Como forma de manter o anonimato dos sujeitos do estudo, seus nomes foram suprimidos pelo código "Contato", acrescido de uma numeração.

Para o desenvolvimento do estudo foram cumpridas as normas éticas, de acordo com a Resolução n.466/12 do Conselho Nacional de Saúde, que dispóe sobre as normas de pesquisas envolvendo seres humanos. Essa Resolução incorpora, sob a ótica do indivíduo e das coletividades, os referenciais da bioética e visa a assegurar os direitos e deveres que dizem respeito aos participantes da pesquisa, à comunidade científica e ao Estado. A pesquisa foi aceita pelo Comitê de Ética em Pesquisa com Seres Humanos do Hospital Universitário Joáo de Barros Barreto, sob o parecer número 867.598.

\section{Resultados e Discussáo}

Os resultados aqui apresentados fundamentam-se no discurso de 40 familiares, sendo 31 mulheres, 21 casadas (os), 27 católicas (os), 20 com o ensino médio completo, 20 entre a faixa etária de 31 a 40 anos. Em relaçáo ao parentesco com o ser hospitalizado, 32 dos familiares possuíam laços de consanguinidade, sendo irmãos (as), mães, pais, filhos (as), primos (as), tios (as) e sobrinhos (as), sendo os demais esposos (as) e noras. Até o momento das entrevistas, o tempo de permanência do ente hospitalizado variou de 3 a 90 dias.

A análise do conteúdo obtido nas observaçóes de campo e nas entrevistas levou à identificação de três categorias descritas a seguir.

\section{Categoria 1: O primeiro contato com o CTI: a importância da comunicaçáa}

O primeiro contato, normalmente, causa uma apreensão no sujeito, ainda mais quando se trata de um lugar cheio de preconcepçóes negativas como um CTI. De acordo com Simoni e Silva (2012), grande parte dos acontecimentos de internaçáo em um CTI são tidos de forma inesperada, culminando em modificaçóes da esfera familiar e imposição aos mesmos de adentrarem no CTI para visitar seu ente querido. Tal situação faz com que muitos familiares cheguem assustados e com medo do que poderáo ver e ouvir em relaçáo ao seu ente hospitalizado.

Nesse contexto, a comunicaçáo é um instrumento fundamental para fomentar novas idealizaçôes do CTI e diminuir as preconcepçôes errôneas trazidas pelos familiares de pacientes internados neste centro, já que a comunicação é composta por elementos facilitadores ou dificultadores no processo das relaçôes interpessoais, podendo exercer influência no modo de agir e de pensar das pessoas envolvidas, de acordo com as próprias mensagens e a maneira como ela é repassada (PUGGINA et al, 2014, HADDAD et al, 2011).

Os relatos aqui descritos informam as avaliaçôes dos familiares sobre a qualidade do primeiro contato com a equipe de saúde do CTI. Sendo essa qualidade configurada em 34 (85\%) das falas como "boa". Tal conceito foi atribuído devido ao recebimento de 
atenção nos momentos de nervosismo e de informaçóes pertinentes à rotina do CTI e do quadro clínico do familiar ali internado, fato este evidenciado nas falas abaixo.

"Foi bom, porque eles me explicaram como era para agir né, que era pra colocar máscara, como colocava, ai eles mandavam lavar as mãos, as vezes a psicóloga também conversa com a gente e explicava os procedimentos, saindo daqui, eles dão o boletim pra gente tudo bonitinho, dizendo como o paciente passou, eu assim eu gostei, achei bem organizado". (Contato 4).

"Na primeira vez que eu vim visitar minha sogra aqui no CTI, a equipe, uma psicóloga na verdade veio falar comigo por que eu estava muito nervosa [...] entáo ela veio e ficou aqui comigo até que eu me recuperasse pra poder voltar lá com minha sogra, e assim, eu gostei, pela atenção que ela me deu sabe”. (Contato 7).

"Bom, porque eles tratam a gente muito bem, eles vem, eu não sabia entrar no CTI, eles me ensinaram como lavava a mão, apropriaram a gente pra ir lá, ensinaram onde era o leito que ela minha irmáo estava, falaram que depois o médico viria, eles passaram informaçóes direitinho, pra mim, foi bom”. (Contato 9).

Conforme evidenciado nas falas, a educação em saúde, aplicada durante o processo de comunicação, cooperou fortemente para que julgassem como bom o serviço a eles dispensados. Haddad et al (2011) relatam em seu estudo que o estabelecimento da comunicação em saúde é algo fundamental para a promoção da saúde e para a formação da cidadania do usuário nas redes de atenção à saúde, exigindo do profissional de saúde envolvido habilidades e atitudes para efetuar a comunicação com a população alvo.

Ser eficaz em comunicação é uma habilidade fundamental a ser adquirida pelos profissionais de enfermagem, pois possibilita um cuidado consciente, verdadeiro e transformador, no qual o profissional poderá identificar os principais significados atribuídos à doença e à hospitalização, pelo paciente e por seus familiares, e assim criar mecanismos que possam ajudar esses indivíduos a vivenciar o acontecimento com menos apreensão e mais tranquilidade. (ANDRADE et al, 2013).

Dentro dos $85 \%$ que consideram o primeiro contato no CTI como bom, também foi possível encontrar em algumas das falas que este bom contato se deu devido à quebra/ mudança de conceitos negativos preexistentes sobre o CTI. Esse fato foi evidenciado nas falas abaixo:

"Foi bom, pude mudar alguns conceitos daqui. Sabe, os pacientes não ficam assim como diz o português claro, eles não ficam jogados aqui, a gente pode fazer a visita e se sentir mais tranquilizado". (Contato 20).

"Eu gostei muito, fiquei surpresa, gostei porque eles são muito humanos, eles perguntam como ela está, eles falam com ela, é bom, eu fiquei surpresa de ser assim". (Contato 24).

Destaca-se, nessas falas, a falta de conhecimento dos familiares sobre o ambiente de terapia intensiva e as preconcepçôes errôneas sobre a realidade da internação em um CTI, baseadas em elementos do senso-comum. Tais pensamentos são cultivados pelo fato do CTI ser, para muitos, um ambiente novo e desconhecido, possuidor de diversos aparelhamentos e de procedimentos desconhecidos e ameaçadores.

Nesse contexto de incertezas, o sentimento de angústia normalmente se instala no familiar devido à separação temporária de seu ente querido a que se vê obrigado e pela sensação de uma possível perda. Tais indícios demostram a necessidade de uma melhoria na comunicação interpessoal entre todos os indivíduos envolvidos na assistência à saúde, incluindo também, nesse contexto, a família. (CASARINI et al, 2013; PUGGINA et al, 2014). 
A orientação familiar antes da visita ao CTI, segundo Oliveira e Nunes (2014), é tida por muitos como a representação do primeiro contato do familiar visitante com o CTI, assim como com o profissional intensivista que, nesse primeiro momento, deve prestar informaçóes à família sobre as condiçóes do paciente, as normas, as rotinas e sobretudo as informaçôes referentes aos horários de visita no CTI.

A necessidade de informaçáo que o familiar possui ao se ver em um CTI, atrelada a um bom acolhimento da equipe de saúde, promove no ser atendido a sensação de que foi bem atendido, assim como no profissional a satisfaçáo do dever cumprindo. No entanto quando essa necessidade de informação não é suprida pela equipe de saúde, o familiar tende a julgar de forma negativa a qualidade do contato estabelecido, sendo que essa avaliação foi encontrada em $15 \%$ dos relatos, como evidenciam as falas a seguir:

"Ruim porque a gente pensa logo no pior, o povo fala, sabe [pausa], ai quando eu cheguei aqui, tive que ficar esperando porque iam fazer um negócio lá com ela [...] eu fiquei muito preocupada, porque eu não sabia o que estava acontecendo com minha mãe, depois eu entrei e quando saí o médico me explicou tudo o que estava acontecendo com ela". (Contato 6).

"Não gostei, porque é a primeira vez que estou aqui, sobre a hora de lavar as mãos e eu não estou sabendo, eu gostaria que tivesse alguma pessoa aqui informando a gente, achei essa dificuldade porque quando a gente precisa de algo [...] a pessoa tem que falar [...] porque a gente fica praticamente desorientado, ansioso [...]". (Contato 36).

Nota-se que os familiares apontam alguns aspectos do contato com a equipe multiprofissional de saúde que os deixaram insatisfeitos, como a ausência de informaçôes com relaçáo ao estado clinico do paciente, da rotina e das normas de biossegurança instituídas no CTI. Tal privação tende a levar o familiar a não reconhecer o profissional do CTI como uma figura de ajuda.

Por esse motivo, os profissionais de saúde, segundo Casarini et al (2013), devem buscar estabelecer uma comunicação clara, constante e que contemple as necessidades de seus clientes, de forma a promover a educação em saúde e mudanças de comportamentos, conceitos e preconceitos sobre o ambiente intensivo. Assim os familiares irão reduzir ou mesmo minimizar a ansiedade diante do enfrentamento da possibilidade da morte, separação e mudanças na rotina de vida vivenciada.

Dessa maneira, lidar com familiares visitantes em um CTI não implica, para a equipe de saúde, em um cuidar a mais, mas o desenvolvimento de habilidades que possibilitam perceber o outro nos seus gestos e falas, assim como em suas ideologias e restriçóes, incluindo no decurso das conversas informaçóes pertinentes de interesse do indivíduo, partilhando responsabilidades e esforços. (PUGGINA et al, 2014).

Em suma, acreditasse que o melhores profissionais de saúde para esses familiares são aqueles que os acolhem e proporcionam o esclarecimento da situação em que seu familiar se encontra, utilizando-se de palavras claras e precisas, que tendem a diminuir os desconfortos vivenciados pelos familiares, acarretando assim uma melhor convivência entre os envolvidos. (ALVES, 2013).

\section{Categoria 2: Quando a equipe de saúde fala comigo!}

Um dos aspectos tidos como mais importante na valorizaçáo do familiar durante o processo de hospitalização de um ente querido, segundo Beuter et al. (2012), é a 
instituição da comunicação entre os familiares e a equipe de saúde, sendo esta aplicada de forma clara e coesa.

Normalmente, alguns profissionais de saúde se deparam com dificuldades para constituir uma boa e eficaz comunicaçáo, dado que em certos momentos da vida se sentem despreparados para lidar com os sentimentos dos pacientes e de seus familiares durante o processo de internação hospitalar, ainda que tenham a consciência de sua importância como recurso terapêutico. (RODRIGUES; FERREIRA; MENEZES, 2010).

No estudo em questáo, todos os familiares informaram que tiveram contato com a equipe de saúde (Médico, Equipe de Enfermagem, Psicóloga e Assistente Social) ou com parte dela todos os dias. O maior contato se deu com os médicos (95\%) por serem os responsáveis pela passagem de informaçóes sobre o estado geral de cada paciente após a visita. Os outros $(5 \%)$ que afirmaram náo terem entrado em contato com os médicos, informaram que realizavam a visita a seus familiares no período da manhã, no qual não é disponibilizado o boletim médico.

O segundo maior contato se deu com a equipe de enfermagem (82,5\%), estabelecido momentos antes da visita, no qual são repassadas as informaçóes sobre o processo de lavagem das mãos e uso de equipamentos de proteção individual como capote e luvas descartáveis, assim como durante a visita ao seu ente querido, em que havia o surgimento de dúvidas.

Por fim, o contato com a psicóloga e a assistente social (55\%), segundo os sujeitos, ocorreu principalmente no primeiro dia antes da visita para colher informaçóes sobre seus familiares ali internados e para os acolher nos momentos de abalo emocional. Apenas $10 \%$ dos sujeitos náo souberam informar detalhes sobre alguns dos profissionais que se comunicaram com eles.

"Nome eu não sei, mas conversei com a enfermeira que estava no momento de plantão, responsável pelo leito do meu marido [...], o médico só fala comigo geralmente no momento do Boletim, a assistente social também me procurou. O psicólogo como eu acredito que um profissional que está mais preparado pra ver o momento crítico que estamos vivendo, ele me procurou no 2 e no 3 dia porque foi um quadro muito difícil do meu marido aqui dentro, acho que eles perceberam o meu estado". (Contato 3).

"Bom as pessoas que falaram comigo foram os técnicos, na hora que eu tinha que entrar, falavam porque eu devia lavar as máos e me davam aquele roupão. A assistente social pra pegar as informaçôes da mamãe e também pra conversar comigo sobre o que estava acontecendo. A enfermeira, bom eu acho que era [risos], todos sempre estão de verde [risos], ela me deu uma lista do que eu podia trazer pra cá, pra mamáe. E o médico só fala comigo no momento do boletim, quando acaba aqui, ele me explica direitinho". (Contato 5).

Através destes relatos, foi possível observar o papel desempenhado, segundo os familiares, pelos profissional do CTI. Na fala do contato 5, é possível destacar a frase "todos sempre estão de verde", a qual demostra que existe uma certa dificuldade por parte dos sujeitos em identificarem os profissionais de saúde que atuam no CTI, haja vista que no local de estudo os mesmos utilizam roupas de mesma coloração sem o uso de um crachá identificativo.

De acordo com Zani et al (2011), a família tem como necessidade a instituição de um vínculo com o profissional de saúde para que o mesmo possa sentir confiança nos procedimentos e condutas tomadas em relação ao seu ente enfermo. No entanto é 
evidente que, em alguns casos, a família não sabe determinar qual é a categoria profissional que lhes fornece as informaçóes.

Instituir uma boa comunicação entre o paciente, o familiar e a equipe de saúde vem sendo uma preocupação constante para que haja uma melhor implementação da humanização da assistência em saúde. (SIMONI; SILVA, 2012). Tal melhoria no processo de comunicaçáo é um assunto de extrema relevância, pois tende a minimizar erros graves como o repasse de informaçóes errôneas. (CRUZ; PEDRO; FASSARELA, 2013).

Segundo Beuter et al (2012), a consolidação de um relacionamento afetivo, respeitoso e solidário entre a equipe de saúde e os familiares de pacientes hospitalizados pode se tornar uma ferramenta terapêutica à medida que a família deposita confiança nos profissionais que promovem assistência ao seu ente querido.

De acordo com as falas dos contatos, também foi observado que a maioria dos contatos se deu de forma mecânica e/ou conforme normas da instituiçáo. A exemplo disso, a passagem do boletim médico, que só é realizado no período da tarde, logo após a visita. Tal situação evidencia a necessidade de instituir novas oportunidades de ouvir o familiar e não apenas se comunicar com ele passando e/ou colhendo informaçóes, ou mesmo dizendo lave as mãos, vista isso ou faça aquilo.

Beuter et al (2012) relatam, em seu estudo, que a interação comunicativa da equipe de saúde com os familiares de pacientes hospitalizados, por vezes, tem sido complexa por haver divergências entre as informaçóes que são partilhadas. Por esse motivo, entende-se que uma relaçáo comunicativa eficaz e coesa entre o familiar e o profissional de saúde ajuda a manter o familiar integrado e consciente das decisóes que poderáo ser tomadas em relação à terapêutica de seu ente enfermo.

Por esse motivo, os profissionais de enfermagem devem se valer da comunicaçáo como um instrumento a mais para o processo de humanizaçáo do cuidado, interagindo com o paciente e com seu familiar, de maneira que vise a esclarecer suas dúvidas quanto à terapêutica, exames e/ou procedimentos clínicos, diminuindo dessa forma a ansiedade e o medo provocado pela doença e pela hospitalizaçáo, pois o familiar também participa do processo de convalescência de seu familiar enfermo.

Assim, atitudes como a prestação de um bom acolhimento, em que se recebe e se ouve os familiares de pacientes hospitalizados, principalmente, daqueles que são internados em um CTI, devem ser executadas sempre que possível em todos os contatos com os familiares, tendo em vista o atender de suas principais necessidades. Tal atitude promoverá de forma natural a criação de vínculos entre o familiar e a equipe de saúde. Nessa relação, o profissional de saúde tornar-se-á ponto de referência e de confiança. (OLIVEIRA, NUNES, 2014).

\section{Categoria 3: Comunicação versus confiança}

No decorrer de toda a história, o ser humano se faz valer dos diversos meios de comunicação para fornecer informaçôes, trocar experiências, ensinar e debater os mais diversos assuntos, assim como para convencer outros, de forma a provocar mudanças de comportamento. (Ramos et al, 2012).

De tal modo, a comunicação em saúde tende a colaborar na qualidade de vida dos indivíduos e na aceitação dos serviços ofertados. No entanto, as respostas podem 
se diferenciar nessas comunicaçóes de acordo com a forma e/ou a maneira adotada pelo profissional ao repassar as informaçôes. (OLIVEIRA et al, 2015).

Segundo a maioria dos sujeitos da pesquisa (90\%), o sentimento de confiança nos profissionais de saúde do CTI foi possível pelo fato de receberem informaçóes importantes sobre seus familiares internados e por terem sanadas suas dúvidas. Os que relataram não confiar (10\%), em parte, da equipe de saúde, essa desconfiança se deu justamente porque não receberam a informação desejada. Observa-se isso nas falas abaixo:

"Senti porque eles explicam bem como o paciente tá, o quadro clinico do paciente entendeu, ai eu perguntava e eles me explicavam nos minimos detalhes, ai a pessoa vai pra casa mais tranquila, porque a gente vai sabendo como esta ela aqui [...]". (Contato 4)

"Olha com os que eu falei sim, porque eles respondem o que a gente pergunta e isso deixa a gente mais calmo, sabe, e a gente confia". (Contato 20).

"Tem um doutor que sinceramente eu náo confio no que ele me fala. Porque sempre quando eu pergunto ele não sabe me responder, é a segunda vez que eu pego ele aqui e toda vez que eu pergunto ele diz - náo sei, ainda vou olhar. O médico tem que ver antes para poder conversar sobre o paciente com a gente [...]”. (Contato 31).

Para se manter ou promover uma boa relação entre a equipe de saúde, o paciente e seu familiar, devem ser incluídos no processo de cuidar técnicas de como repassar informaçôes, a exemplo, quais os procedimentos que poderão ser realizados, através de uma linguagem clara e direta, assim como disponibilizar aos pacientes e seus familiares a oportunidade de dialogar sobre suas dúvidas e sobre os sentimentos neles despertados com o processo de hospitalização. (CRUZ; PEDRO; FASSARELA, 2013).

Segundo pesquisas, o processo de internação em um CTI desperta nos familiares sentimentos de dor e angústia. Estes, por sua vez, sentem a necessidade de informaçóes claras que lhes permitam compreender o que está acontecendo com seu ente querido, visto ser essa uma das formas que encontram para diminuir a dor e angústia. Assim os familiares tendem a procurar respostas junto aos profissionais de saúde, identificando aqueles com que podem contar, conforme o retorno obtido. (GIRARDON-PERLINI et al, 2012; FREITAS, MUSSI, MENEZES; 2012).

Ramos et al (2012) diz que é importante estabelecer um vínculo de confiança e de compreensão entre os familiares e os profissionais de saúde para que haja uma boa relação entre eles. Para tanto, a comunicaçáo realizada deve estar adaptada às aptidóes cognitivas, ao nível cultural, social e educacional e às necessidades emocionais de cada indivíduo.

A comunicação, quando utilizada de forma clara e objetiva por parte da equipe de saúde, tende a contribuir para a qualidade e humanização dos cuidados, assim como produzir uma aproximaçáo com o ser envolvido, podendo despertar no mesmo o sentimento de confiança, segurança e satisfação com relação ao atendimento e o cuidado recebido. (ANDRADE et al, 2013; RAMOS et al, 2012).

Dessa maneira, a necessidade de segurança está vinculada às necessidades de sentirse seguro e menos angustiado quanto ao estado clínico e prognóstico de seu parente. Tal situação aponta para a necessidade da implementaçáo de medidas que visem a disponibilidade de informaçóes sobre a real situação do paciente, dos cuidados ali realizados, das rotinas do CTI e também oferecer orientações que possam contribuir para o bem-estar do paciente e de seu familiar.

Ramos et al (2012), em seu estudo sobre comunicação em saúde e interculturalidade, evidenciaram que a instituição de uma boa comunicação entre o profissional de saúde e seu 
cliente promove força ao familiar/paciente para lidar com a doença, com a hospitalizaçáo, reduz estados depressivos, conserva a dignidade e o respeito, assim como gera a satisfação e o sentimento de segurança entre os envolvidos.

No entanto a quebra de confiança no profissional de saúde por falta de informaçóes, segundo observado no depoimento do "contato 31", tende a dificultar uma convivência harmoniosa durante o período de internaçáo de seu ente enfermo. Tal falha, na maioria dos casos, ocorre devido à equipe intensivista focar sua atenção na rotina complexa do CTI e na prestação de serviços de alta tecnologia, o que faz com que a mesma passe a apresentar menor interesse nas relaçóes pessoais. (ZANI et al, 2011; AGUIAR et al, 2012).

Através de todo o exposto, evidencia-se a necessidade de criar ou reservar um maior espaço de tempo para o repasse de informaçóes e escuta ativa desses familiares, tendo como intuito diminuir seus medos e pesares, assim como promover neles a sensação de segurança e amparo pelos profissionais de saúde do CTI. Segundo Haddad et al (2011), a comunicação entre o profissional enfermeiro e o usuário não deve ser apenas social, mas também terapêutico. $\mathrm{O}$ enfermeiro deve demostrar empatia e respeito ao usuário atendido.

\section{Conclusão}

Conclui-se que a comunicaçáo em saúde, quando utilizada de maneira adequada, é uma excelente ferramenta de trabalho no cuidado em saúde, pois promove uma maior interação entre a equipe e o ser assistido, facilitando a criação de vínculos de confiança e obtendo um melhor grau de satisfaçáo nos serviços ofertados, tanto pelo cliente como pela equipe que presta o serviço.

O estudo também mostrou que é necessário rever as estratégias utilizadas para capacitar a equipe de saúde, para que estes possam recepcionar e acolher da melhor forma os familiares e amigos dos pacientes internados no CTI, durante os horários de visita, para assim suprir as necessidades conforme forem identificadas.

No CTI de estudo, há dois anos, já se vem transmitindo algumas informaçôes por meio de folhetos educativos sobre os cuidados ali ofertados, atividade que foi instituída pelo projeto de extensão intitulado "O cotidiano dos familiares de pacientes internados no CTI". A estratégia foi adotada para complementar e facilitar a comunicação em saúde entre os bolsistas/voluntários e os familiares visitantes, assim como para facilitar a compreensáo por parte dos familiares sobre o ambiente de terapia intensiva e suas peculiaridades.

Após a execuçáo da pesquisa, comprovou-se a necessidade de se manter a execução das atividades previstas pelo projeto, assim como se viu a necessidade de repassar as informaçóes e experiências colhidas para a equipe de saúde do CTI, de forma a incentivalos a melhorar a forma com a qual se dirigiam aos familiares e a refletirem em suas condutas, visando um atendimento em saúde aos familiares de pacientes internados no CTI mais adequado e humanizado.

No entanto, este é apenas um projeto de extensão que no final de seu curso, se não for renovado, deixará de existir. Assim, necessita-se que os gestores de saúde avaliem a importância de se instituir, de maneira fixa, tal estratégia, de forma a promover uma 
melhor interaçáo da equipe com os familiares e facilitar o processo de enfrentamento e superação desses familiares através das informações prestadas. Que essa estratégia não se prenda apenas ao CTI, mas que se multiplique em todos os âmbitos da saúde, uma vez que todos têm necessidades de receber informaçóes.

\section{Referências}

AGUIAR, A. S. C; et al. Percepção do enfermeiro sobre promoção da saúde na Unidade de Terapia Intensiva. Revista da Escola de Enfermagem USP, São Paulo, v. 46, n. 2, p. 428-35. 2012.

ALVES, E. F. O Cuidador de Enfermagem e o Cuidar em Uma Unidade de Terapia Intensiva. UNOPAR Científica Ciências Biológicas e da Saúde, v. 15, n. 2, p.115-22. 2013

ANDRADE, M. A; et al. Comunicação no contexto hospitalar como estratégia para a segurança do paciente: Revisão integrativa. Revista Rede de Cuidados em Saúde, v. 7, n. 1. 2013.

BARDIN, L. Análise de conteúdo. Edições 70, LDA, Lisboa, Portugal. 2009.

BEUTER, M; et al. Sentimentos de familiares acompanhantes de adultos face ao processo de hospitalização. Escola Anna Nery (impr.), v. 16, n. 1, p. 134-140. Jan-mar. 2012.

BRASIL. Resolução no 466. Dispõe sobre pesquisa com seres humanos. Publicada no DOU no 12. Seção 1, p. 59. 13 jun 2013. Disponível em: <http://conselho.saude.gov.br/ resolucoes/2012/Reso466.pdf>. Acesso em: 04 de Nov. 2015.

CASARINI, K. A; et al. Análise qualitativa do uso de manual informativo para familiares em UTI. SPAGESP - Sociedade de Psicoterapias Analíticas Grupais do Estado de São Paulo. Revista da SPAGESP, v. 14, n. 2, p. 55-72. 2013.

CRUZ, D. S. M; PEDRO, S. L. B; FASSARELA, C. S. A comunica ação entre equipe de enfermagem e acompanhante visando à segurança do paciente oncológico durante 0 processo de hospitalização. Revista Rede de Cuidados em Saúde. v. 7, n. 1. 2013.

DAHDAH, D. F. et al Grupo de familiares acompanhantes de pacientes hospitalizados: estratégia de intervenção da Terapia Ocupacional em um hospital geral. Caderno de Terapia Ocupacional UFSCar, São Carlos, v. 21, n. 2, p. 399-404, 2013.

HADDAD, J. G. V; et al. A comunicação terapêutica na relação enfermeiro-usuário da atenção básica: um instrumento para a promoção da saúde e cidadania. $\mathbf{O}$ Mundo da Saúde, São Paulo, v. 35, n. 2, p. 145-155. 2011. 
FREITAS, K. S; MUSSI, F. C; MENEZES, I. G. Desconfortos Vividos no Cotidiano de Familiares de Pessoas Internadas na UTI. Escola Anna Nery (impr), v. 16, n. 4, p. 704-11. Out-dez. 2012.

GIRARDON-PERLINI, N. M. O; et al. Percepções e sentimentos da família na interação com a equipe de enfermagem na UTI neonatal. Ciência Cuidado e Saúde, v. 11, n. 1, p. 26-34. Jan-Mar. 2012.

OLIVEIRA, C. N; NUNES, E. D. C. A. Cuidando da família na UTI: desafio de enfermeiros na práxis interpessoal do acolhimento. Texto Contexto Enfermagem, Florianópolis, v. 23, n. 4, p. 954-63. Out-Dez. 2014.

OLIVEIRA, L. A, et al. Discursos em saúde. A comunicação a serviço de quem? In: 40 Congresso IberoAmericano em Investigação Qualitativa. E 60 Simpósio Internacional de Educação e Comunicação. Atas CIAIQ2015, v. 1, 2015, p. 452-4.

OLIVEIRA, N.E.S. Humanização do cuidado em terapia intensiva: saberes e fazeres expressos por enfermeiros. Dissertação (Mestrado). Universidade Federal de Goiás, Faculdade de Enfermagem - Programa de Pós-Graduação em Enfermagem. 2012. Disponível em:<http://mestrado.fen.ufg.br/ uploads/127/original_Nara_Elizia_Souza_de_Oliveira.pdf?1391017634>. Acesso em: 08 de Out. 2015.

PUGGINA, A. C; et al. Percepção da comunicação, satisfação e necessidades dos familiares em Unidade de Terapia Intensiva. Escola Anna Nery, v. 18, n. 2, p. 277-83. Abr-Jun. 2014.

RAMOS, M. N. P. Comunicação em Saúde e Interculturalidade - Perspectivas Teóricas, Metodológicas e Práticas. Ensaio. RECIIS - Revista Eletrônica de Comunicação, Informação e Inovação em Saúde, v. 6, n. 4, p. 1-19. Dez. 2012.

RODRIGUES, M. V. C; FERREIRA, E. D; MENEZES, T. M. O. Comunicação da enfermeira com pacientes portadores de câncer fora de possibilidade de cura. Revista de enfermagem UERJ. Rio de Janeiro, v. 18, n. 1, p. 86-91. 2010.

SIMONI, R. C. M; SILVA, M. J. P. O impacto da visita de enfermagem sobre as necessidades dos familiares de pacientes de UTI. Revista da Escola de Enfermagem USP, v. 46 (Especial), p. 65-70. 2012.

ZANI, A. V; et al. As interfaces da convivência da família em uma unidade de pronto socorro. Ciência Cuidado e Saúde, v. 10, n. 4, p. 803-11. 2011. 